\title{
Effects of Worked Examples in a Primary School Mathematics Curriculum
}

Citation for published version (APA):

Van Gog, T., Brand-Gruwel, S., \& Van Loon-Hillen, N. (2012). Effects of Worked Examples in a Primary School Mathematics Curriculum. Interactive LearnIng Environments, 20(1), 89-99.

https://doi.org/10.1080/10494821003755510

DOI:

$10.1080 / 10494821003755510$

Document status and date:

Published: 01/02/2012

Document Version:

Peer reviewed version

Please check the document version of this publication:

- A submitted manuscript is the version of the article upon submission and before peer-review. There can be important differences between the submitted version and the official published version of record. People interested in the research are advised to contact the author for the final version of the publication, or visit the DOI to the publisher's website.

- The final author version and the galley proof are versions of the publication after peer review.

- The final published version features the final layout of the paper including the volume, issue and page numbers.

Link to publication

\section{General rights}

Copyright and moral rights for the publications made accessible in the public portal are retained by the authors and/or other copyright owners and it is a condition of accessing publications that users recognise and abide by the legal requirements associated with these rights.

- Users may download and print one copy of any publication from the public portal for the purpose of private study or research.

- You may not further distribute the material or use it for any profit-making activity or commercial gain

- You may freely distribute the URL identifying the publication in the public portal.

If the publication is distributed under the terms of Article 25fa of the Dutch Copyright Act, indicated by the "Taverne" license above, please follow below link for the End User Agreement:

https://www.ou.nl/taverne-agreement

Take down policy

If you believe that this document breaches copyright please contact us at:

pure-support@ou.nl

providing details and we will investigate your claim.

Downloaded from https://research.ou.nl/ on date: 26 Apr. 2023 
Running head: WORKED EXAMPLES

Please cite as:

Van Loon-Hillen, N., Van Gog, T., \& Brand-Gruwel, S. (2010). Effects of Worked Examples in a Primary School Mathematics Curriculum. Interactive Learning Environments, 18, 1-11.

Effects of Worked Examples in a Primary School Mathematics Curriculum

Nelleke van Loon-Hillen ${ }^{\mathrm{a}}$, Tamara van Gog ${ }^{\mathrm{a}, \mathrm{b}}$, and Saskia Brand-Gruwel ${ }^{\mathrm{a}}$

${ }^{a}$ Centre for Learning Sciences and Technologies, Open University of The Netherlands

${ }^{\mathrm{b}}$ Institute of Psychology, Erasmus University Rotterdam, The Netherlands

Author Note:

Correspondence concerning this manuscript should be addressed to Tamara van Gog, Institute of Psychology, Erasmus University Rotterdam, P.O. Box 1738, 3000 DR Rotterdam, The Netherlands. T: +31 10408 8799; F: +31 10 4089009; E: vangog@ fsw.eur.nl

Acknowledgements. During the realization of this work, Tamara van Gog was supported by a Veni Grant from the Netherlands Organization for Scientific Research (\# 45108-003). The authors would like to thank the teachers involved in this study for their cooperation. 
About the authors. Nelleke van Loon, MSc, conducted this study as partial fulfilment of the requirements for her Master degree in Learning Sciences from the Open University of The Netherlands.

Tamara van Gog, $\mathrm{PhD}$, was formerly at the Open University of The Netherlands, and is currently associate professor of Educational Psychology at the Institute of Psychology of the Erasmus University Rotterdam.

Saskia Brand-Gruwel, $\mathrm{PhD}$, is associate professor of Educational Technology at the Centre for Learning Sciences and Technologies of the Open University of The Netherlands. 


\begin{abstract}
A large body of research has shown that for novice learners, instruction that relies more heavily on worked examples than on problem solving, is more effective for learning as shown by higher test performance. Moreover, this beneficial effect is often obtained with less acquisition time and lower cognitive load during acquisition and test phase. However, most of this research has been conducted in lab settings with college or university students and a control condition consisting of problem solving without any additional support. The present study, using a quasi-experimental design, investigated the effects of implementing worked examples in an existing primary school mathematics curriculum in which a realistic mathematics teaching method is used, during a three week period. Results showed no significant differences in test performance or cognitive load; however, the worked examples group attained this level of performance with significantly less acquisition time.
\end{abstract}




\section{Effects of Worked Examples in a Primary School Mathematics Curriculum}

The present study investigated the effects of implementing worked examples in an existing primary school mathematics curriculum in which a realistic mathematics method is used, over a 3-week period. Despite the popularity of 'learning by doing' in contemporary education, a large body of research has shown that for students who lack prior knowledge of a task, self-directed problem solving is not the most efficient way to acquire knowledge. It is far more effective and efficient for novice learners to study a good example (see Atkinson, Derry, Renk1, \& Wortham, 2000; Sweller, 2006; Sweller, Van Merriënboer, \& Paas, 1998). This has become known as 'the worked example effect', which cognitive load theory has explained the effectiveness of worked examples in terms of reduced ineffective load on working memory (Sweller, 1988; Sweller et al., 1998).

\section{Cognitive Load Theory}

Cognitive load theory (Sweller, 1988; Sweller et al., 1998) is concerned with the design of instructional methods that efficiently use people's limited cognitive processing capacity. The theory distinguishes three types of cognitive load: Intrinsic, extraneous, and germane load. Intrinsic load depends on the complexity of a task, that is, on the number of interacting information elements the task contains (Chandler \& Sweller, 1991). These elements have to be processed simultaneously in order to successfully learn to perform that kind of task. Because working memory capacity is limited to seven plus or minus two elements (or chunks) of information when merely holding information (Miller, 1956) and even fewer (ca. four) when processing information (Cowan, 2001), the higher this number of interacting information elements is, the higher the intrinsic load imposed on working memory is. However, intrinsic load does not solely depend on the nature of the task, but also on the level of expertise of the learner. As expertise increases, information elements contained in the task become incorporated into cognitive schemata stored in long-term memory. Because a 
schema retrieved from long-term memory can be handled in working memory as a single element, the number of interacting information elements a task contains, and hence, the intrinsic load it imposes, decreases for more knowledgeable learners. With extended practice, certain schemata can be automated and no longer require controlled, effortful processing, which further reduces the load on working memory (Schneider \& Shiffrin, 1977).

Extraneous and germane load both depend on the way the task is designed, with extraneous load being imposed by processes that are evoked by the design of the task that are ineffective for learning (e.g., unnecessary visual or mental search processes; Chandler \& Sweller, 1991) and germane load being imposed by processes evoked by the design of the task that do contribute to learning (e.g., imagining a solution procedure; Cooper, Tindall-Ford, Chandler, \& Sweller, 2001). The central tenet of cognitive load theory is that in order to be effective and efficient, instruction should be designed in such a way that intrinsic load is optimized, that is, tasks should be at an appropriate level of complexity for trainees (i.e., challenging, but feasible; cf. Vygotsky's, 1978, concept of the Zone of Proximal Development), extraneous load is minimized, and germane load is optimized so that the available cognitive capacity is optimally used (Sweller et al., 1998). An effective instructional technique to accomplish this is to implement a heavier reliance on worked example study rather than problem solving.

\section{Effectiveness of Worked Examples}

Conventional problems contain only a description of some "givens" (e.g., how fast a car accelerates and its average velocity) along with a goal statement (e.g., 'calculate how far the car has travelled'). Instruction that consists mainly of solving conventional problems forces novices to resort to weak problem-solving strategies such as means-ends analysis, which impose a high cognitive load but are not effective for learning: even though such weak strategies may allow learners to succeed in solving the problem eventually (i.e., performance), 
they have been shown to contribute very little to learning (Sweller, 1988), that is, to building a cognitive schema of how such problems should be solved. Worked examples prevent the use of such weak problem-solving strategies, by presenting the learner not only with the givens and a goal statement, but also with the worked-out solution steps that are to be taken to reach the goal state. The learner can devote all his or her available cognitive capacity to studying the given solution and constructing a cognitive schema for solving such problems. As such, compared to instruction consisting of conventional problem solving, instruction that relies more heavily on studying worked examples reduces ineffective cognitive load on working memory, and enhances learning, as well as transfer. That is, students not only learn how to solve identical problems, but also (partly) novel problems, for which they have to flexibly adapt the learned solution procedure (see Sweller et al., 1998). In addition to enhanced learning and transfer (i.e., higher test performance), a heavier reliance on worked examples has also been shown to have beneficial effects on required acquisition time (i.e., lower; see e.g., Sweller \& Cooper, 1985; Van Gog, Paas, \& Van Merriënboer, 2006; Zhu \& Simon, 1987) and cognitive load experienced by students during acquisition (i.e., lower; see e.g., Paas \& Van Merriënboer, 1994; Van Gog et al., 2006) as well as during the test (i.e., lower; see e.g., Paas, 1992; Paas \& Van Merriënboer, 1994).

It should be noted though, that these beneficial effects of worked examples on learning, acquisition time, and cognitive load, seem to apply primarily to novice learners, and only when the examples are well-designed. To start with the latter, following the early studies on worked examples by Sweller and Cooper (1985) and Cooper and Sweller (1987), it was soon discovered that studying worked examples was not always more effective for learning than problem solving. Rather, the design of the examples played a crucial role in their effectiveness (Tarmizi \& Sweller, 1988). If worked examples induced split attention, by presenting mutually referring information sources such as text and picture/diagram separately, 
a worked example effect (i.e., benefit over learning by problem solving) was not obtained. Presumably, this was due to extraneous cognitive load imposed by the processes of dividing attention (i.e., visual search) and mental integration that were required in order to learn from the separate sources of information. When these information sources were presented in an integrated manner, the worked example effect was again obtained (Tarmizi \& Sweller, 1988; reduction of extraneous load due to split attention can also be done by providing spoken rather than written text with the pictorial information in the example; Mousavi, Low, \& Sweller, 1995). On the other hand, when information sources are not mutually referring and can be easily understood in isolation, extraneous cognitive load is imposed by the need to process redundant information. In this case, one of the information sources should be left out (see Chandler \& Sweller, 1991). Next to these basic requirements for the design of worked examples, there are some design measures that can be applied to enhance the effectiveness of examples even further, by stimulating more active processing of the examples or emphasizing important aspects of the procedure (i.e., increase germane load; Paas \& Van Gog, 2006), such as making subgoals explicit through labeling or visually isolating sets of steps (e.g., Catrambone, 1995), requiring students to complete steps in partially worked-out examples (e.g., Paas, 1992), asking students to explain the principles behind the worked-out solution steps for themselves (e.g., Chi, Bassok, Lewis, Reimann, \& Glaser, 1989; Renkl, 1997), or providing them with instructional explanations (e.g., Lovett, 1992; Renkl, 2002) or problemsolving process information (e.g., Van Gog, Paas, \& Van Merriënboer, 2008) that help them understand the principles behind the solution steps.

Next to design, prior knowledge also plays a role in the effectiveness of worked examples. As mentioned above, with increasing expertise, the intrinsic load imposed by the task becomes lower. As a consequence, extraneous load might no longer have negative effects, as enough cognitive capacity is available to deal with the task aspects that impose 
extraneous load. Moreover, techniques that may successfully reduce extraneous load for novice learners, such as studying worked examples, may increase extraneous load for more knowledgeable learners. That is, because of their prior knowledge, studying the worked-out solution is a redundant, unnecessary cognitive activity. As a consequence, for advanced learners, worked examples may no longer be effective, or may even start to hamper learning (e.g., Kalyuga, Chandler, Tuovinen, \& Sweller, 2001). This is an example of what is known as the 'expertise reversal effect' (for a review, see Kalyuga, 2007; Kalyuga, Ayres, Chandler, \& Sweller, 2003).

In sum, the worked example effect indicates that when examples are well-designed, instruction that relies more heavily on example study is more effective, efficient, or both, for novices than instruction consisting of problem solving. A 'heavier reliance' on example study has been implemented differently in different studies, though. Some authors have compared instruction consisting only of studying examples to instruction consisting of problem solving (e.g., Van Gerven, Paas, Van Merriënboer, \& Schmidt, 2002; Van Gog et al., 2006, 2008), whereas others have used example-problem pairs, arguing that this would be more motivating for students (e.g., Cooper \& Sweller, 1987; Sweller \& Cooper, 1985), or two examples-one problem triplets (Paas, 1992). Others have used problem-example pairs, arguing that this allows students to experience where their difficulties with problem solving occur, so that they would subsequently study the example more closely (e.g., Stark, Gruber, Renkl, and Mandel (2000; for a discussion of their study in English see Stark, Gruber, Hinkofer \& Mandl, 2004). Finally, a heavier reliance on example study has been implemented by providing students with examples that are available for students to use as an analogy while they are solving a problem (e.g., Reed, Dempster, \& Ettinger, 1985), which is also the approach taken in this study.

The Present Study 
Although the effects of worked examples on mathematics learning has been widely studied (e.g., Carroll, 1994; Cooper \& Sweller, 1987; Mwangi \& Sweller, 1998; Reed et al., 1985; Sweller \& Cooper, 1985; Zhu \& Simon, 1987), research consists mostly of short-term experimental studies (i.e., conducted in one or two sessions); there are very few studies done in actual school curricula over a longer period of time (for an exception, see e.g., Zhu \& Simon, 1987). Moreover, most of the research on learning from worked examples has been conducted with college or university students, and very little with primary school age children (for an exception, see e.g., Mwangi \& Sweller, 1998). Finally, the control condition in previous research usually consisted of problem solving by oneself without any additional instructional support or guidance, not of the teaching methods regularly used in schools, which might be a stronger control condition (cf. Schwonke, Renkl, Krieg, Wittwer, Aleven, \& Salden, 2009).

Therefore, the present study investigated the effects of implementing a heavier reliance on worked examples by providing them as analogies for problem solving in an existing primary school mathematics curriculum in which a realistic mathematics teaching method is used, over a 3-week period. The focus during this period was on subtraction problems with borrowing 10s and 100s. Such problems contain many interacting information elements, so they impose a high intrinsic cognitive load for students, and -probably as a consequence- many errors may occur, such as subtracting digits in the wrong order, trying to borrow from zero rather than the column to the left, not carrying tens or hundreds, etc. (see Peltenburg, Van den Heuvel-Panhuizen, \& Doig, 2009). Based on previous research, it is hypothesized that the availability of worked examples as an analogy for problem solving, will lead to lower acquisition time, lower cognitive load during acquisition and test phase, and higher test performance. 


\section{Participants and Design}

Participants were 45 fourth-grade Dutch primary school students (age $M=9.9$ years; $S D=0.34)$. They were students from two existing classes of the same school. A quasiexperimental design was used in which one class $(n=23)$ was assigned as experimental group and one class $(n=22)$ as control group.

\section{Materials}

Subtraction instruction. This primary school uses a realistic mathematics teaching method called 'RekenRijk' (Bokhove, Kuipers, \& Postema, 2003). This method consists of 12 blocks per year. This study focused on block 6 , in which subtracting with borrowing 10 s and 100s is taught. This block consists of 12 lessons (4 teaching lessons, 6 self-study lessons, 1 repetition lesson, and 1 'deepening understanding' lesson). Six of those lessons were devoted to subtracting with borrowing 10 s and 100 s according to the problem format $787-492=\ldots$ (i.e., in the other lessons, other problem types such as word problems were used), so data from these lessons are used in the analyses.

The control group engaged in their regular instruction and self-study using the RekenRijk method materials. The experimental group also engaged in their regular instruction and self-study with the RekenRijk method and materials, but additionally received two worked examples on subtracting with borrowing (one on borrowing 10s and one on borrowing 100s), which were explained by the teacher in the first lesson and were handed out to each student so that they could consult these examples as an analogy for problem solving throughout the acquisition phase.

Cognitive load rating scale. The most common method of measuring cognitive load in educational research is via subjective rating scales (Paas, Tuovinen, Tabbers, \& Van Gerven, 2003). An illustrated 4-point cognitive load rating scale was developed for this age group, asking students to indicate how "heavy" they found the tasks they just completed, ranging 
from (1) not at all (a drawing of a child carrying one block above her head and smiling), to (4) very heavy (a drawing of a child carrying four blocks above her head looking sad).

Time-on-task. Students were asked to write down their start and end times on the pretest and posttest and for each lesson according to a digital alarm clock that was placed in such a way that it was clearly visible for all students.

Pretest and posttest. To measure participants' knowledge gain, the regular 'Block Test' for Block 6 from the 'RekenRijk' method (Bokhove et al., 2003) was used. Twenty items from this test concerned subtracting with borrowing 10s and 100s similar to the problems that were worked out in the examples, so these 20 items were used to determine test performance in the context of this study.

Example experience questionnaire. To get an impression of how students in the worked examples condition experienced working with the examples, a short self-report questionnaire was used, with answer options 'no', 'don't know' or 'yes', that asked students: 1) whether the examples were clear, 2) whether they felt problem solving was easier when using the examples, 3) whether they felt they required less assistance during problem solving when using the examples, 4) whether they used the examples with every problem, 5) whether they would want to use examples also with other types of problems.

\section{Procedure}

Prior to the study, the teachers received information about how to proceed in their respective condition. In the control group, this meant engaging in instruction as usual, except for the pretest and the cognitive load and time on task measures that were added for this study. In the experimental group, this additionally included information for the teachers on how to implement the examples. Students were also acquainted with the cognitive load and time on task measurement procedure prior to the study, and they were informed that the pretest (which was added for this study) would not be taken into account in determining their 
progress report scores. At the start of the 3-week period, participants first completed the pretest, indicating their perceived cognitive load immediately after completing the test. Then, for 3 weeks, they engaged in the learning activities of Block 6 of the RekenRijk method, either with or without the additional worked examples depending on their assigned condition. For each lesson, students indicated their start and end time according to the digital clock, and at the end of each lesson rated their perceived cognitive load. Finally, all students completed the posttest, again indicating their perceived cognitive load immediately after completing the test. In the week after the post-test, the students in the worked examples condition completed a short questionnaire about their experience working with the examples.

\section{Results}

Means and standard deviations of performance, cognitive load, and acquisition time are presented in Table 1. A repeated measures analysis on pretest and posttest performance showed -as one would expect- a significant reduction in the amount of errors made (max. = $20)$ from pretest $(M=15.98, S D=6.26)$ to posttest $(M=5.91, S D=4.85), F(1,42)=101.94$, $M S E=21.89, p<.001$; however, there was no significant interaction with group $F(1,42)<1$, $n s$. That is, in contrast to our hypothesis, the worked examples group did not outperform the control group on the posttest.

A repeated measures analysis on perceived cognitive load during pretest and posttest showed -as one would expect given the increase in knowledge- a significant reduction in the perceived cognitive load from pretest $(M=2.70, S D=1.03)$ to posttest $(M=1.61, S D=.78)$, $F(1,42)=39.69, M S E=.66, p<.001 ;$ however, there was no significant interaction with group $F(1,42)<1, n s$. That is, in contrast to our hypothesis, the worked examples group did not experience lower cognitive load than the control group on the posttest.

An ANOVA showed that in contrast to our hypothesis, perceived cognitive load during the acquisition phase in the six lessons on subtraction with borrowing did not differ 
between the experimental group and the control group, $F(1,38)<1$, ns (4 participants were excluded from this analysis due to missing data on one or more of the lessons). However, in line with our hypothesis, there was a significant difference in acquisition time during those lessons ( 5 participants were excluded from this analysis due to missing data on one or more of the lessons), with acquisition time in the experimental group being lower than in the control group, $F(1,38)=6.28, p=.017$.

Descriptive statistics of the examples experience questionnaire data are provided in Table 2. Not taking into account the "don't know" answers, it can be concluded that all students found the examples clear, and the majority of students reported they found problem solving easier when using the examples, felt they required less assistance from a teacher or peer when using the examples, would like to work with examples also with other types of math problems, and that they had not used the examples as an analogy with every problem they solved.

\section{Discussion}

This study aimed to investigate the effects of implementing a heavier reliance on worked examples in an existing primary school mathematics curriculum over a 3-week period. It was hypothesized that a heavier reliance on worked examples would lead to lower acquisition time, lower cognitive load during acquisition and test phase, and higher knowledge gains (i.e., difference between pretest and posttest scores). This hypothesis was only partially confirmed: No differences in test performance or cognitive load were found between the groups, but the worked examples group did require less acquisition time.

Even though there were no differences in perceived cognitive load between the two groups, the measure that was developed for this study seems to be adequate for use with relatively young children, and seems to show construct validity. That is, for people without any prior knowledge, as was the case at the time of the pretest, problem solving tasks impose 
a much higher intrinsic load than for people who do have prior knowledge of the tasks, as was the case at the time of the posttest. As indicated in the introduction, with increasing practice, interacting information elements that a task contains are combined into cognitive schemata that can be handled in working memory as a single element, which reduces the amount of intrinsic load imposed by a task. Moreover, with increasing practice, problem-solving procedures can become automated, which further reduces working memory load. The measures of perceived cognitive load used in this study reflect the decrease in cognitive load one would expect with increasing knowledge/practice. However, a scale with more answer options might have provided more sensitivity to detect potential subtle differences in cognitive load during the acquisition phase.

There are several possible explanations for the finding that the only difference between the groups lay in the required acquisition time, whereas a lot of previous studies have also shown beneficial effects on learning. First of all, the realistic mathematics teaching method used by this school as well as the ecologically valid setting of this study which included not only self-study but also teacher instruction may have provided a stronger control group than normally used in studies on the effectiveness of worked examples. That is, in most studies, the control condition usually consists of solving problems by oneself without any additional instruction or guidance for students. The study by Schwonke et al. (2009) which also used a stronger control condition, that is, problem solving guided by a cognitive tutoring system, also showed positive effects of worked examples mainly in terms of lower acquisition time. Secondly, students were given only two worked examples to use as analogies for problem solving and even though these two examples were illustrative for both problem categories (i.e., borrowing 10s and borrowing 100s), the fact that they were always the same may have reduced their motivation to actively process them over the course of the three weeks. Finally, and this is a limitation of this study, we do not have any data on the extent to 
which the students used the examples and when they used them. The self-report data on the questionnaire suggest that students did not use them with every problem they solved. Given that we know that worked examples are more effective in the initial stages of skill acquisition, and tend to become redundant when students have gained prior knowledge of the task (the expertise reversal effect; Kalyuga, 2007; Kalyuga et al., 2003), and that our students' knowledge levels did increase in the course of this study, as shown by the performance and cognitive load data on the pretest and posttest, it would have been interesting to have data on whether students indeed consulted the examples more in the beginning of the study. It would be interesting to complement the self-report data with observation data in future studies, to get information on when and how students use worked examples as an analogy for problem solving.

Nonetheless, the finding that providing worked examples as an analogy for problem solving in an ecologically valid setting, reduces the time required for attaining the same level of performance is interesting for educational practice: by implementing examples, time can be gained that can be used for repetition or other activities. Moreover, providing some examples as analogies for problem solving is very easy to implement and does not require a lot of development time from the teachers; indeed, if students' self-report data on their reduced need for assistance are accurate, providing students with worked examples might even save teachers some time. As mentioned in the introduction, there are other ways of implementing a heavier reliance of worked examples than providing them to be used as an analogy during problem solving (in which case they are an addition to problem solving). An interesting question for future research would be whether replacing part of the problems from the teaching method with worked examples would enhance learning. Research suggests that a completion or fading strategy (Renkl \& Atkinson, 2003) might be a good way of doing this. In a completion or fading strategy, completion problems (i.e., partially worked-out examples 
that leave some solution steps open for the learner to complete; Paas, 1992), provide a bridge between studying fully worked-out examples and solving the entire problem oneself. So, this strategy takes into account the learners' developing expertise, by starting instruction with studying worked examples, and proceeding via completion problems with increasingly more steps to be completed by the learner, to having learners solve problems on their own. 


\section{References}

Atkinson, R. K., Derry, S. J., Renkl, A., \& Wortham, D. (2000). Learning from examples: Instructional principles from the worked examples research. Review of Educational Research, 70, 181-214.

Bokhove, J., Kuipers, K., \& Postema, J. (2003). RekenRijk: Didactisch handboek [RekenRijk: Didactical manual]. Groningen, The Netherlands: Wolters-Noordhoff.

Carroll, W. M. (1994). Using worked out examples as an instructional support in the algebra classroom. Journal of Educational Psychology, 86, 360-367.

Catrambone, R. (1995). Aiding subgoal learning: Effects on transfer. Journal of Educational Psychology, 87, 5-17.

Chandler, P. \& Sweller, J. (1991). Cognitive load theory and the format of instruction. Cognition and Instruction, 8, 293-332.

Chi, M. T. H., Bassok, M., Lewis, M. W., Reimann, P., \& Glaser, R. (1989). Selfexplanations: How students study and use examples in learning to solve problems. Cognitive Science, 13, 145-182.

Cooper, G., Tindall-Ford, S., Chandler, P., \& Sweller, J. (2001). Learning by imagining. Journal of Experimental Psychology: Applied, 7, 68-82.

Cooper, G., \& Sweller, J. (1987). The effects of schema acquisition and rule automation on mathematical problem-solving transfer. Journal of Educational Psychology, 79, 347362.

Cowan, N. (2001). The magical number 4 in short-term memory: A reconsideration of mental storage capacity. Behavioral \& Brain Sciences, 24, 87-114.

Kalyuga, S. (2007). Expertise reversal effect and its implications for learner-tailored instruction. Educational Psychology Review, 19, 509-539.

Kalyuga, S., Chandler, P., Tuovinen, J., \& Sweller, J. (2001). When problem solving is 
superior to studying worked examples. Journal of Educational Psychology, 93, 579588.

Kalyuga, S., Ayres, P., Chandler, P., \& Sweller, J. (2003). The expertise reversal effect. Educational Psychologist, 38, 23-32.

Lovett, M. C. (1992). Learning by problem solving versus by examples: The benefits of generating and receiving information. In: Proceedings of the 14th annual conference of the Cognitive Science Society (pp. 956-961). Hillsdale, NJ: Erlbaum.

Miller, G. A. (1956). The magical number seven, plus or minus two: Some limits on our capacity to process information. Psychological Review, 63, 81-97.

Mousavi, S. Y., Low, R., \& Sweller, J. (1995). Reducing cognitive load by mixing auditory and visual presentation modes. Journal of Educational Psychology, 87, 319-334.

Mwangi, W., \& Sweller, J. (1998). Learning to solve compare word problems: The effect of example format and generating self-explanations. Cognition and Instruction, 16, 173199.

Paas, F. (1992). Training strategies for attaining transfer of problem-solving skill in statistics: A cognitive load approach. Journal of Educational Psychology, 84, 429-434.

Paas, F., Tuovinen, J. E., Tabbers, H., \& Van Gerven, P. W. M. (2003). Cognitive load measurement as a means to advance cognitive load theory. Educational Psychologist, $38,63-71$.

Paas, F., \& Van Gog, T. (2006). Optimising worked example instruction: Different ways to increase germane cognitive load. Learning and Instruction, 16, 87-91.

Paas, F., \& Van Merriënboer, J. J. G. (1994). Variability of worked examples and transfer of geometrical problem solving skills: A cognitive-load approach. Journal of Educational Psychology, 86, 122-133. 
Peltenburg, M., Van den Heuvel-Panhuizen, M., \& Doig, B. (2009). Mathematical power of special-needs pupils: An ICT-based dynamic assessment format to reveal weak pupils' learning potential. British Journal of Educational Technology, 40, 273-284.

Reed, S. K., Dempster, A., \& Ettinger, M. (1985). Usefulness of analogous solutions for solving algebra word problems. Journal of Experimental Psychology: Learning, Memory, and Cognition, 11, 106-125.

Renkl, A. (1997). Learning from worked-out examples: A study on individual differences. Cognitive Science, 21, 1-29.

Renkl, A. (2002). Learning from worked-out examples: Instructional explanations supplement self-explanations. Learning \& Instruction, 12, 149-176.

Renkl, A. \& Atkinson, R. K. (2003). Structuring the transition from example study to problem solving in cognitive skills acquisition: A cognitive load perspective. Educational Psychologist, 38, 15-22.

Schneider, W., \& Shiffrin, R. M. (1977). Controlled and automatic human information processing: I. Detection, search, and attention. Psychological Review, 84, 1-66.

Schwonke, R., Renkl, A., Krieg, K., Wittwer, J., Aleven, V., \& Salden, R. (2009). The worked-example effect: Not an artefact of lousy control conditions. Computers in Human Behavior, 25, 258-266.

Stark, R., Gruber, H., Hinkofer, L., \& Mandl, H. (2004). Overcoming problems of knowledge application and transfer. In H. P. A. Boshuizen, R. Bromme, \& H. Gruber (Eds.), Professional learning: Gaps and transitions on the way from novice to expert (pp. 4970). Dordrecht, The Netherlands: Kluwer Academic.

Stark, R., Gruber, H., Renkl, A. \& Mandl, H. (2000). Instruktionale Effekte einer kombinierten Lernmethode: Zahlt sich die Kombination von Lösungsbeispielen und Problemlöseaufgaben aus? [Instructional effects of a combined learning method: Does 
the combination of worked-out examples and problem-solving tasks pay off?] Zeitschrift für Pädagogische Psychologie, 14, 205-217.

Sweller, J. (1988). Cognitive load during problem solving: Effects on learning. Cognitive Science, 12, 257-285.

Sweller, J. (2006). The worked example effect and human cognition. Learning and Instruction, 16, 165-169.

Sweller, J., \& Cooper, G. A. (1985). The use of worked examples as a substitute for problem solving in learning algebra. Cognition and Instruction, 2, 59-89.

Sweller, J., Van Merriënboer, J. J. G., \& Paas, F. (1998). Cognitive architecture and instructional design. Educational Psychology Review, 10, 251-295.

Tarmizi, R., \& Sweller, J. (1988). Guidance during mathematical problem solving. Journal of Educational Psychology, 80, 424-436.

Van Gerven, P. W. M., Paas, F., Van Merriënboer, J. J. G., \& Schmidt, H. G. (2002).

Cognitive load theory and aging: Effects of worked examples on training efficiency. Learning and Instruction, 12, 87-105.

Van Gog, T., Paas, F., \& Van Merriënboer, J. J. G. (2006). Effects of process-oriented worked examples on troubleshooting transfer performance. Learning and Instruction, 16, 154164.

Van Gog, T., Paas, F., \& Van Merriënboer, J. J. G. (2008). Effects of studying sequences of process-oriented and product-oriented worked examples on troubleshooting transfer efficiency. Learning and Instruction, 18, 211-222.

Vygotsky, L. S. (1978). Mind in society. Cambridge, MA: Harvard University Press.

Zhu, X., \& Simon, H. A. (1987). Learning mathematics from examples and by doing. Cognition and Instruction, 4, 137-166. 
Table 1

Means and Standard Deviations of Performance, Cognitive Load, and Acquisition Time

\begin{tabular}{|c|c|c|c|c|}
\hline & \multicolumn{2}{|c|}{ Control } & \multicolumn{2}{|c|}{ Worked Examples } \\
\hline & $M$ & $S D$ & $M$ & $S D$ \\
\hline Pretest Performance (number of errors, $\max .=20 ;$ lower $=$ better $)$ & 15.90 & 6.43 & 16.04 & 6.24 \\
\hline Pretest Cognitive Load (max. $=4)$ & 2.76 & 1.00 & 2.65 & 1.07 \\
\hline Cognitive Load Acquisition (max. $=4$ ) & 1.62 & 0.50 & 1.66 & 0.52 \\
\hline Acquisition Time (min.) & 33.80 & 5.40 & 29.44 & 5.43 \\
\hline Posttest Performance (number of errors, $\max .=20 ;$ lower $=$ better) & 5.52 & 4.43 & 6.26 & 5.27 \\
\hline Posttest Cognitive Load (max. $=4$ ) & 1.62 & 0.87 & 1.61 & 0.72 \\
\hline
\end{tabular}


Table 2

Answers to Example Study Experience Questionnaire $(n=22$, data from 1 participant missing due to absence)

\begin{tabular}{lcccc}
\hline \multicolumn{1}{c}{ Question } & No & Don't Know & Yes & Proportion Yes/Yes+No \\
\hline Were examples clear? & 0 & 2 & 20 & $100.00 \%$ \\
Problem solving easier when using examples? & 4 & 5 & 13 & $76.47 \%$ \\
Less assistance required when using examples? & 5 & 5 & 2 & $70.59 \%$ \\
Examples used with every problem? & 10 & 10 & 12 & $16.67 \%$ \\
Want examples also with other problems? & 3 & 7 & $80.00 \%$ \\
\hline
\end{tabular}

